\title{
Utilization of porous dolomite pellets for the catalytic decomposition of acetic acid
}

\author{
Yelian Miao $^{a, *}$, Jun Xue ${ }^{a}$ Fajun Xia $^{a}$, Xiuli Yin ${ }^{b, * *}$, Chuangzhi $\mathrm{Wu}^{b}$ \\ a State Key Laboratory of Materials-Oriented Chemical Engineering, College of Life Science and Pharmaceutical Engineering, Nanjing \\ University of Technology, NO. 5 Xinmofan Road, Nanjing, Jiangsu 210009, China \\ ${ }^{\mathrm{b}}$ The Renewable Energy and Gas Hydrate Key Laboratory of CAS, Guangzhou Institute of Energy Conversion, Chinese Academy of Sciences, \\ Guangzhou 510640, China
}

\section{A R T I C L E I N F O}

\section{Article history:}

Received 20 July 2008

Received in revised form

16 May 2010

Accepted 21 July 2010

Available online 17 August 2010

\section{Keywords:}

Biomass gasification

Tar

Acetic acid

Catalyst

Dolomite

Pellet

\begin{abstract}
A B S T R A C T
Catalytic decomposition of tar is a novel technology to clean the gas produced by biomass gasification. The purpose of the present research work was to develop strong and porous pellets of dolomite catalyst for tar decomposition. Porous dolomite pellets of $3 \mathrm{~mm}$ in diameter and $4 \mathrm{~mm}$ in height were prepared with dolomite, carboxyl methyl cellulose (CMC) and clay. The mechanical strength, the pore rate and the catalytic effect of porous dolomite pellets on decomposition of acetic acid were investigated. When the clay/dolomite mass ratio was 0.4 and the $\mathrm{CMC}$ /dolomite mass ratio was 0.2 , the porous dolomite pellets had a mechanical strength of $15 \mathrm{~N}$ and a pore rate of $0.75 \mathrm{~cm}^{3} \mathrm{~g}^{-1}$. The pore size had approximately a normal distribution in the range of $0.06-200 \mu \mathrm{m}$. Under the condition of gas residence time at $7.5 \mathrm{~s}$ and bed temperature at $800{ }^{\circ} \mathrm{C}, 99.7 \mathrm{wt} \%$ of acetic acid was decomposed over the porous dolomite pellets, but only $36.5 \mathrm{wt} \%$ of acetic acid was decomposed with natural dolomite particles. It was indicated that the porous dolomite pellets were much more effective than the natural dolomite particles for catalyzing the decomposition of tar to gas.
\end{abstract}

(c) 2010 Elsevier Ltd. All rights reserved.

\section{Introduction}

Recently, biomass has been studied as a potential energy source, because the energy shortage and the environmental problems caused by the use of fossil fuels become more and more severe. Gasification technologies are used to convert biomass to fuel gas by heating it in a gasification medium such as air, oxygen, or steam. The product gas can be used in many fields, such as the generation of heat or electricity, and the synthesis of liquid fuels and chemicals [1,2].

Although the main components of the gas produced are $\mathrm{H}_{2}$, $\mathrm{CO}, \mathrm{CO}_{2}, \mathrm{CH}_{4}$, and $\mathrm{H}_{2} \mathrm{O}$, etc., the generation of tar is also inevitable in the biomass gasification process. The tar content in the gas depends on the feedstock, the processing method and the operating conditions. Using a fluidized bed gasifier, for example, $1 \mathrm{~m}^{3}$ produced gas (under the normal condition of $100 \mathrm{kPa}$ and $298.15 \mathrm{~K}$ ) usually contains 5-75 g of tar [3]. Tar contained in the gas condenses when the bed temperature is lower than its dew point that is normally $300{ }^{\circ} \mathrm{C}$ [4]. The condensed tar may deposit and thus cause damage in pipelines, compressors, gas engines and turbines, which results in increased maintenance cost. Moreover, the tar contains a significant amount of energy that should be able to be transferred to fuel gas such as $\mathrm{H}_{2}, \mathrm{CO}, \mathrm{CH}_{4}$, etc.

\footnotetext{
* Corresponding author. Tel.: +86 0258317 2064; fax: +86 02583587356.

** Corresponding author. Tel.: +86 0208705 7731; fax: +86 02087057737 .

E-mail addresses: ylmiao@njut.edu.cn (Y. Miao), xlyin@ms.giec.ac.cn (X. Yin). 0961-9534/\$ - see front matter @ 2010 Elsevier Ltd. All rights reserved.

doi:10.1016/j.biombioe.2010.07.019
} 
The tar content must be reduced before the produced gas is further processed. Among the usual methods to reduce the tar content such as decomposition, filtration and scrub, decomposition is a more attractive approach, because it has the potential to increase the total energy efficiency of gasification, and simultaneously eliminate the need for the collection and disposal of $\operatorname{tar}[1]$.

In the tar decomposition process, dolomite is often used as a catalyst, because of its high catalytic activity, low cost, and large amount of storage in the earth in comparison with alkali metals and nickel, etc [5-7]. By blending 2 wt\% of dolomite with biomass as the feedstock in gasification process, the tar content can be significantly decreased, and the hydrogen yield can be increased [8]. It has also been reported that the product gas was cleaned and the total product gas yield was increased by using calcined dolomite both in-bed and downstream of a biomass gasifier [7,9]. Thermogravimetric analysis (TGA) results showed that the catalytic effect of calcined dolomite on tar decomposition changed with the mass ratio of $\mathrm{CaO}$ to $\mathrm{MgO}$. The activation energy of tar decomposition reaction was reduced from $20.9 \mathrm{~kJ} \mathrm{~mol}^{-1}$ to $16.5 \mathrm{~kJ} \mathrm{~mol}^{-1}$, when the calcined dolomite contained about $50 \%$ of $\mathrm{MgO}$ [10]. However, calcined dolomite particles are fragile, so they can be easily crushed to fine particles under the impact/attrition of gas flow and other objects. The crushing of dolomite particles may lead to the problems such as pressure drop through a blockade in a fixed bed and loss as fly ash in a fluidized bed [11]. Therefore, further research is needed to improve the properties of dolomite particles.

Tar is a complex mixture of a large number of compounds, including acids, aldehydes, alcohols, ketones, substituted furans derived from cellulose and hemi-cellulose, and phenolic and cyclic oxygenates derived from lignin. The water phase of tar contains $17.8 \%$ of acetic acid [12]. Because of its large content, acetic acid has often been used as a model compound in the selection of optimized operating conditions and the performance test of catalysts for tar decomposition $[13,14]$.

The present research work was carried out to make strong and porous pellets of dolomite catalyst for the tar decomposition in biomass gasification process. Porous dolomite pellets were prepared with dolomite, clay and carboxyl methyl cellulose (CMC). Effects of $\mathrm{CMC} /$ dolomite mass ratio on mechanical strength and pore rate in the porous dolomite pellets were investigated. Catalytic effect of the porous dolomite pellets on acetic tar decomposition was evaluated using acetic acid as a model compound, in comparison with that of natural dolomite particles.

\section{Materials and methods}

\subsection{Preparation of porous dolomite pellets}

Porous dolomite pellets were prepared following the procedure of mixing, molding, drying and calcining [15]. Dolomite powder under a 200 mesh Tyler sieve (Yanxin Mineral Processing Co., Ltd, China) contained $54.0 \% \mathrm{CaCO}_{3}$ and $42.7 \%$ $\mathrm{MgCO}_{3}$. It was mixed with clay (Gaolin Clay Co., Ltd, China) at a clay/dolomite mass ratio of 0.4 , and carboxyl methyl cellulose (CMC) (Boli Chemical Industry Co., Ltd, China) at a $\mathrm{CMC} /$ dolomite mass ratio ranging from 0 to 0.4 in a stainless steel basin. The clay contained $37 \% \mathrm{Al}_{2} \mathrm{O}_{3}, 48 \% \mathrm{SiO}_{2}$ and $0.6 \%$ $\mathrm{Fe}_{2} \mathrm{O}_{3}$.

A small-scale extruder (TBL-2, Baiyang Chemical Engineering Experimental Equipment Co. in Tianjin University, China) was used to make cylindrical pellets of $3 \mathrm{~mm}$ in diameter and $4 \mathrm{~mm}$ in height. The pellets were dried at the room temperature for $12 \mathrm{~h}$ followed by calcination at $900^{\circ} \mathrm{C}$ for $4 \mathrm{~h}$ under air atmosphere. Carbonates, the main components of dolomite, were converted to oxides, and the CMC was removed during the calcinations.

\subsection{Measurement of physical properties}

Mechanical strength, pore size distribution and pore rate of the prepared porous dolomite pellets were measured.

A particle hardness tester (GWJ-1, Hangzhou Tuopu Instrument Co., Ltd., China) was used to measure the mechanical strength. Each pellet sample was compressed in its axial direction, and the force required to destroy the pellet sample was recorded. The mechanical strength was determined by averaging the compression forces of 20 pellet samples.

An automatic mercury porosimeter (Poromaster GT-60, Quantachrome, USA) was used for measuring the pore size distribution and the pore rate. Mercury pressure varied in the range of $9.65 \mathrm{kPa}-159 \mathrm{MPa}$ at the room temperature.

\subsection{Catalytic decomposition}

Acetic acid in liquid phase (purity $>99.5 \%$, Shantou Xilong Chemicals, China) was used as a model compound to investigate the catalytic effect of the porous dolomite pellets on tar decomposition.

Experimental apparatus used for the catalytic decomposition of acetic acid is shown in Fig. 1. The reactor $(40 \mathrm{~mm}$ in interior diameter, $300 \mathrm{~mm}$ in height) was made of stainless steel

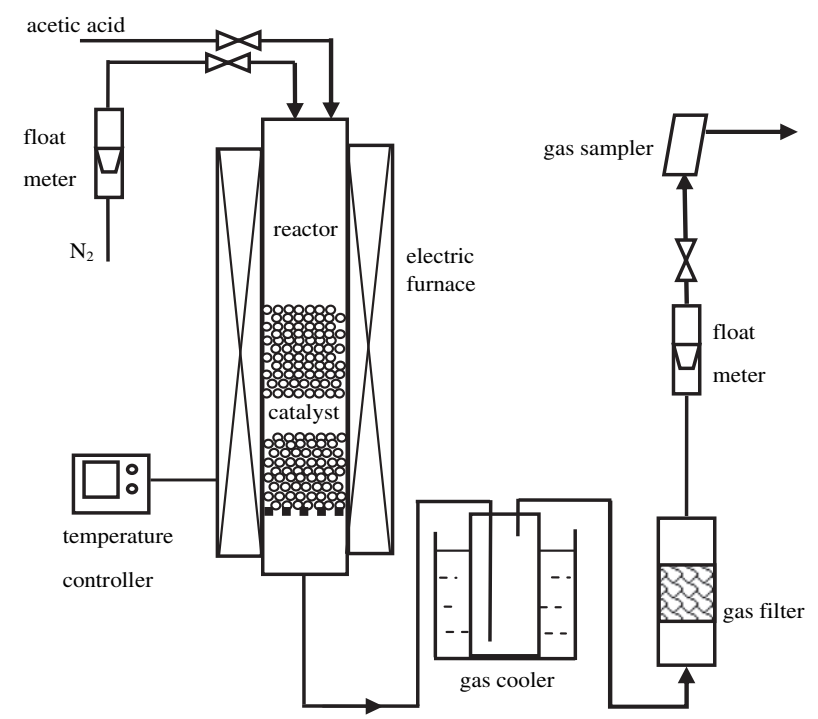

Fig. 1 - Schematic diagram of the experimental apparatus. Y. Miao et al. 
type 310 , and heated by an electric furnace. It had a perforated plate with $2.0 \%$ fractional open area at the bottom for supporting the catalyst. The gas cooler was used to cool the product gas and collect the unreacted acetic acid. Porous dolomite pellets prepared with a clay/dolomite mass ratio of 0.4 and a $\mathrm{CMC} /$ dolomite mass ratio of 0.2 were used as the catalyst, and 4-10 mesh (1.70-4.75 mm) natural dolomite particles (Yanxin Mineral Processing Co., Ltd, China) were used as the control. The natural dolomite particles were also calcined at $900{ }^{\circ} \mathrm{C}$ for $4 \mathrm{~h}$ under air atmosphere before use. For each run, $117 \mathrm{~g}$ of the catalyst was packed in the reactor, which formed a catalyst bed of $200 \mathrm{~mm}$ in height. Nitrogen gas was introduced into the reactor from the top as carrier gas. The bed temperature was varied in the range of $600-850^{\circ} \mathrm{C}$, and the gas residence time was varied in the range of $3.8-30 \mathrm{~s}$ (corresponding to a carrier gas flow rate in the range of $4-0.5 \mathrm{~L} \mathrm{~min}^{-1}$ ).

Acetic acid was fed into the reactor with a peristaltic pump (BT50-1J, Baoding Longer Precision Pump Co., Ltd., China). The feeding rate was controlled at $1 \mathrm{~mL} \mathrm{~min}^{-1}$. In the reactor, acetic acid was decomposed to gas and coke. The product gas was sampled with a gas-sampling bag, and its composition $\left(\mathrm{H}_{2}, \mathrm{CH}_{4}, \mathrm{O}_{2}, \mathrm{CO}, \mathrm{CO}_{2}\right)$ was analyzed on a gas chromatograph (GC2010, Shimadzu Corporation, Japan). The flow rates of the inlet gas $\left(\mathrm{N}_{2}\right)$ and the outlet gas $\left(\mathrm{N}_{2}\right.$ and product gas) were respectively measured by float meters. The coke produced in acetic acid decomposition mainly deposited on the internal wall of reactor and the surface of catalysts. The coke deposit on the internal wall of reactor was directly collected and weighed after the decomposition test, while the coke deposit on the surface of catalysts was measured by weighing the catalysts before and after the decomposition test.

The yield of each gas component, $Y_{i}(\%)$, was calculated as follows:

$Y_{i}=\frac{C_{i} Q \rho_{i} t}{100 \times m_{a}} \times 100 \%$

where, $C_{i}$ : the concentration of gas $i$, vol\%; Q: the flow rate of total product gas at $298.15 \mathrm{~K}, \mathrm{~L}_{\mathrm{min}}^{-1} ; \rho_{\mathrm{i}}$ : the density of gas $i$ at $298.15 \mathrm{~K}, \mathrm{~g} \mathrm{~L}^{-1}$; $t$ : time, min; $m_{a}$ : the mass of acetic acid supplied, $g$.

The yield of total product gas was expressed by the summation of the yields of all gas components.

On the other hand, the coke yield, $Y_{c}(\%)$, was calculated as follows:

$\mathrm{Y}_{\mathrm{c}}=\frac{m_{\mathrm{c}}}{m_{a}} \times 100 \%$

where, $m_{c}$ : the mass of coke deposit, $g$.

\section{Results and discussion}

\subsection{Mechanical strength}

Mechanical strength of the porous dolomite pellets is shown in Fig. 2 as a function of the $\mathrm{CMC} /$ dolomite mass ratio. The standard deviation of the data for each mechanical strength value was smaller than $0.26 \mathrm{~N}$. The mechanical strength was $85 \mathrm{~N}$ when no CMC was used, and it decreased to $3.5 \mathrm{~N}$ when the $\mathrm{CMC} /$ dolomite mass ratio was 0.4 . In comparison with the

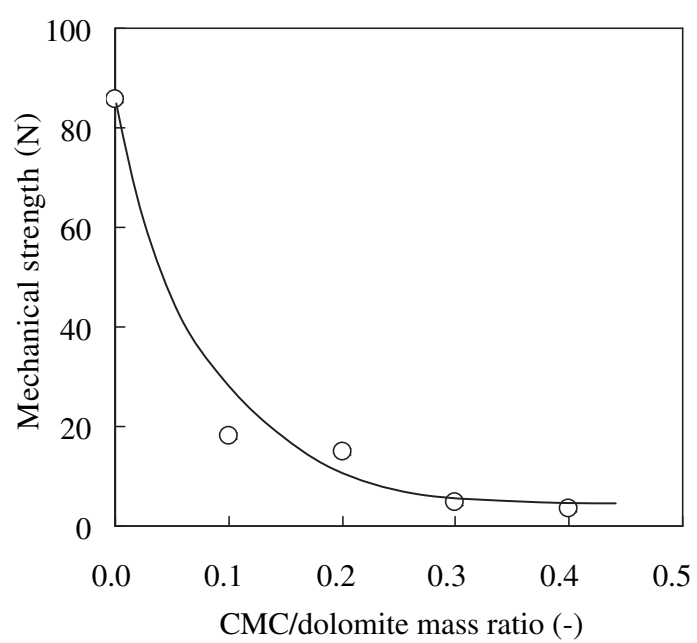

Fig. 2 - Changes of mechanical strength with CMC/ dolomite mass ratio of the porous dolomite pellets (clay/ dolomite mass ratio: 0.4 ). Y. Miao et al.

mechanical strength of natural dolomite particles $(0.8 \mathrm{~N})$ [11], it is obvious that the mechanical strength of natural dolomite particles was significantly increased by the pelletizing process.

\subsection{Pore rate}

As shown in Fig. 3, pore rate in the porous dolomite pellets increased linearly with increasing of $\mathrm{CMC} /$ dolomite mass ratio. The pore ratio was $0.35 \mathrm{~cm}^{3} \mathrm{~g}^{-1}$ when no CMC was used, and it increased to $1.02 \mathrm{~cm}^{3} \mathrm{~g}^{-1}$ when the $\mathrm{CMC} /$ dolomite mass ratio increased to 0.4 . The porous structure was formed due to the removal of CMC during the calcination process.

Roughly, pore size in the porous dolomite pellets followed a normal distribution. For the porous dolomite pellets with a $\mathrm{CMC} /$ dolomite mass ratio of 0.2 , the pore size distributed in the range of $0.06-200 \mu \mathrm{m}$ (Fig. 4). The relative pore rate reached to a maximum of $2.0 \%$ at a pore size of $0.42 \mu \mathrm{m}$. These pore features were similar with those of active carbon.

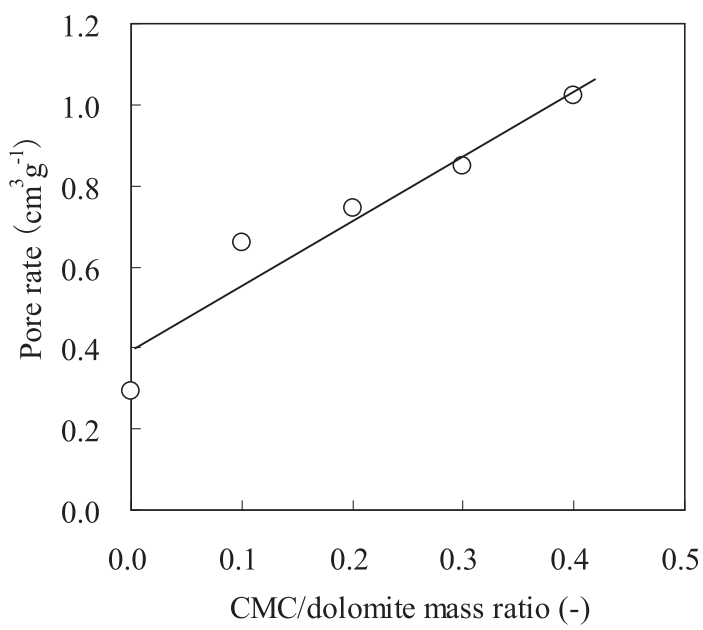

Fig. 3 - Changes of pore rate with $\mathrm{CMC} /$ dolomite mass ratio of the porous dolomite pellets (clay/dolomite mass ratio: 0.4). Y. Miao et al. 


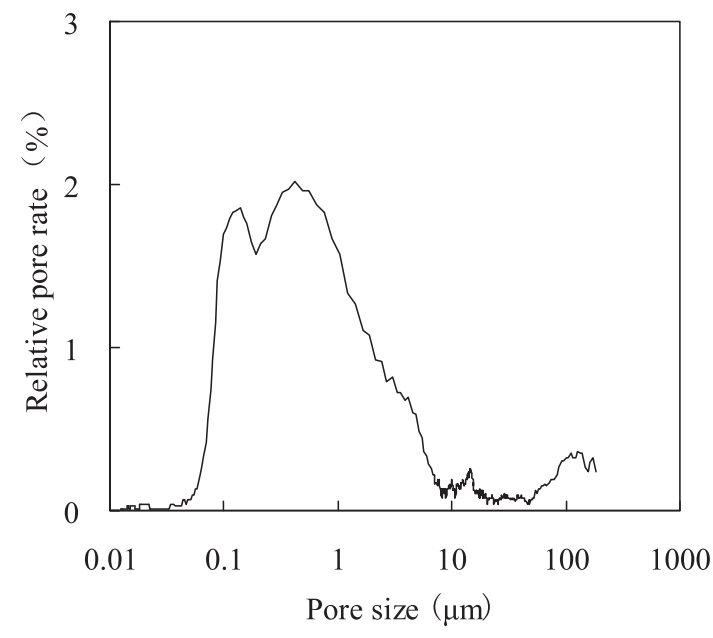

Fig. 4 - An example of pore size distribution in the porous dolomite pellets (CMC/dolomite mass ratio: 0.2, clay/ dolomite mass ratio: 0.4 ). Y. Miao et al.

Natural dolomite particles usually have micropores of $0.9-4 \mathrm{~nm}$ in diameter and a pore rate of $0.34-0.41 \mathrm{~cm}^{3} \mathrm{~g}^{-1}$ after calcination $[6,9]$. It can be found that both the pore size and the pore rate in the porous dolomite pellets are much larger than those in natural dolomite particles.

\subsection{Catalytic effect on acetic acid decomposition}

The changes of $\mathrm{H}_{2}, \mathrm{CH}_{4}, \mathrm{O}_{2}, \mathrm{CO}, \mathrm{CO}_{2}$ concentrations during acetic acid decomposition over the porous dolomite pellets are shown in Fig. 5. No $\mathrm{H}_{2}, \mathrm{CH}_{4}, \mathrm{O}_{2}, \mathrm{CO}, \mathrm{CO}_{2}$ was detected before feeding of acetic acid, which indicated that the reactor was airtight. The $\mathrm{H}_{2}, \mathrm{CH}_{4}, \mathrm{O}_{2}, \mathrm{CO}, \mathrm{CO}_{2}$ concentrations started to increase when acetic acid was fed into the reactor, and became constant after $10 \mathrm{~min}$. The gas flow rate and the gas concentrations under the constant condition were used in the calculation of the gas yield.

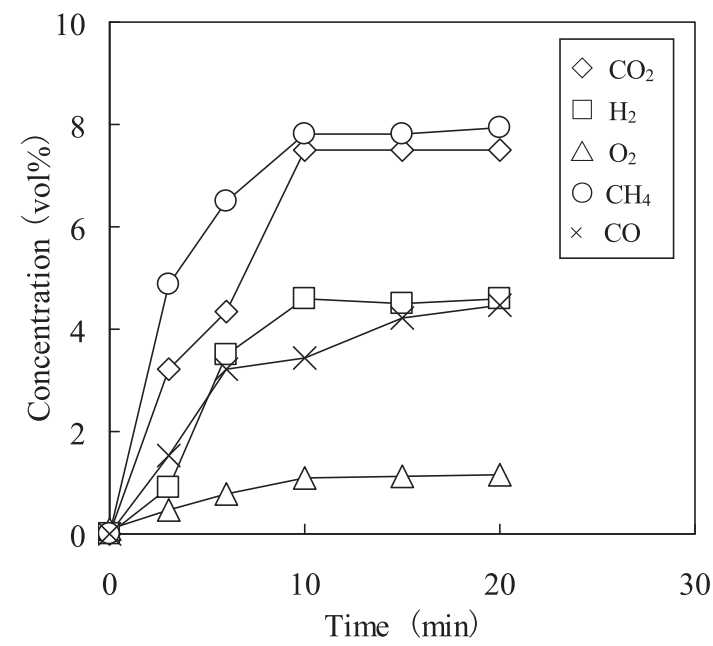

Fig. 5 - Changes of gas concentrations during acetic acid decomposition over the porous dolomite pellets (bed temperature: $800{ }^{\circ} \mathrm{C}$, gas residence time: $7.5 \mathrm{~s}$ ). Y. Miao et al.

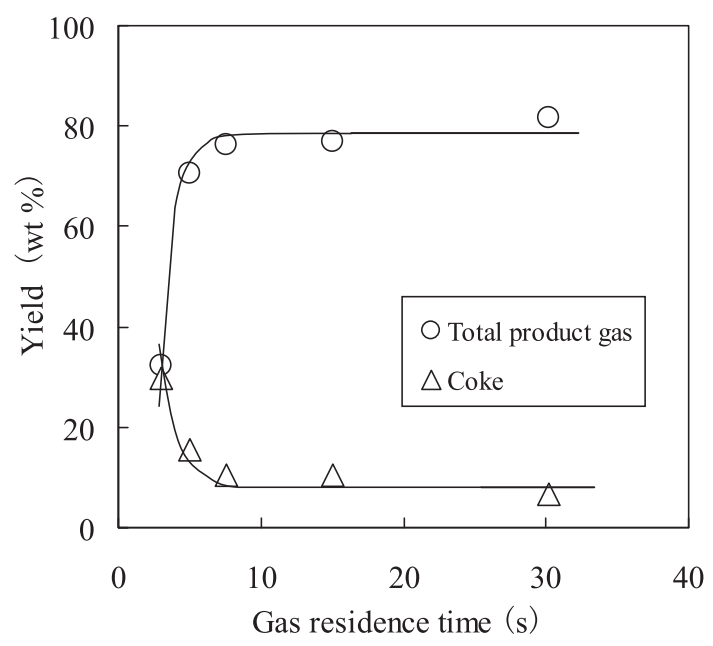

Fig. 6 - Effect of gas residence time on acetic acid decomposition over the porous dolomite pellets (bed temperature: $700{ }^{\circ} \mathrm{C}$ ). Y. Miao et al.

The decomposition of acetic acid over the porous dolomite pellets was affected by the gas residence time (Fig. 6) and the bed temperature (Fig. 7). The total product gas yield increased with increasing of gas residence time and bed temperature at first, and then it became constant when the gas residence time was longer than $7.5 \mathrm{~s}$ and the bed temperature was higher than $800{ }^{\circ} \mathrm{C}$. A high yield of total product gas was associated with a low yield of coke. Most of unreacted acetic acid was condensed and collected in the gas cooler. For all the tests, the overall recovery of total product gas, coke and unreacted acetic acid was higher than $95 \%$.

The yields of total product gas and coke in acetic acid decomposition over the natural dolomite particles and the porous dolomite pellets are compared in Fig. 8, when the gas residence time is $7.5 \mathrm{~s}$ and the bed temperature is $800^{\circ} \mathrm{C}$. Over the porous dolomite pellets, the total product gas yield was $91.3 \mathrm{wt} \%$ and coke yield was $8.0 \mathrm{wt} \%$, indicating that the acetic

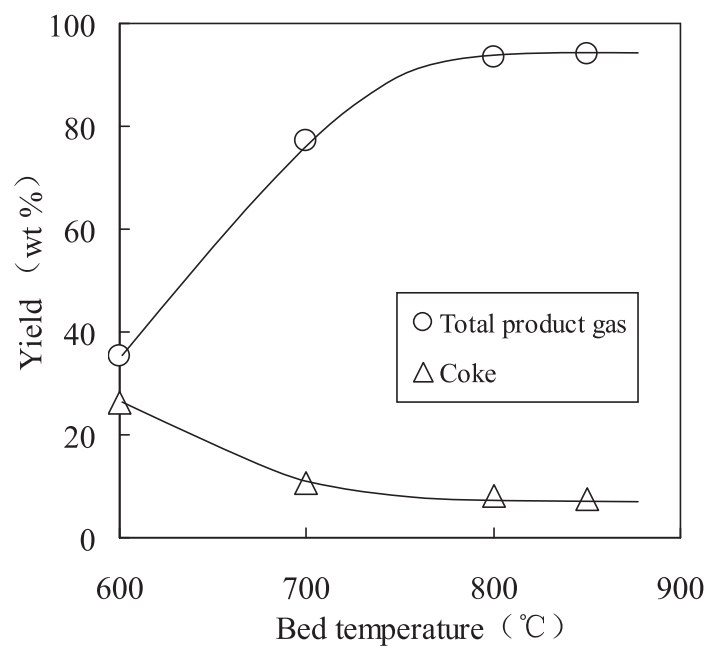

Fig. 7 - Effect of bed temperature on acetic acid decomposition over the porous dolomite pellets (gas residence time: $7.5 \mathrm{~s}$ ). Y. Miao et al. 


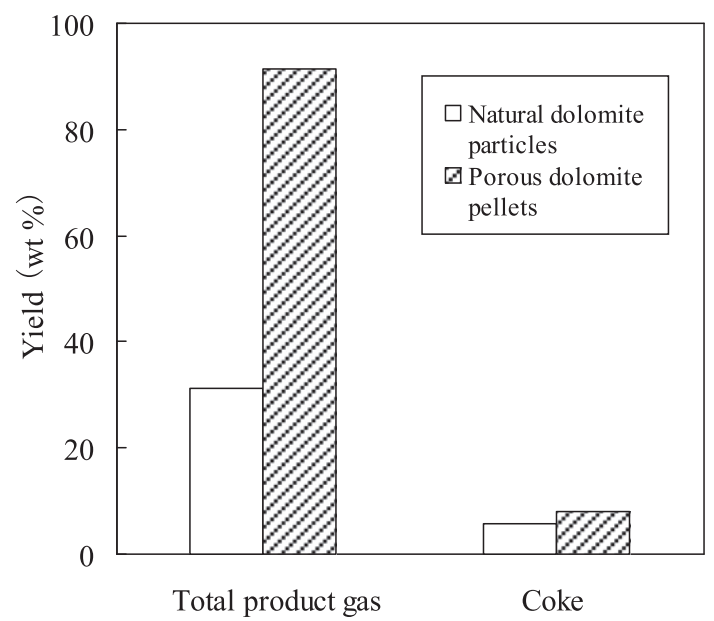

Fig. 8 - Comparison of the yields of total product gas and coke in acetic acid decomposition over different catalysts (bed temperature: $800^{\circ} \mathrm{C}$, gas residence time: $7.5 \mathrm{~s}$ ). Y. Miao et al.

acid supplied was almost completely decomposed. On the other hand, the natural dolomite particles only had a total product gas yield of $30.8 \mathrm{wt} \%$ and a coke yield of $5.7 \mathrm{wt} \%$. It indicates that the porous dolomite pellets were more effective than the natural dolomite particles in catalyzing the decomposition of acetic acid, as well as tar, to gas.

The yields of each gas component in acetic acid decomposition over the two different catalysts are shown in Table 1. In comparison with those over the natural dolomite particles, $\mathrm{H}_{2}, \mathrm{O}_{2}, \mathrm{CO}$ and $\mathrm{CO}_{2}$ increased considerably, although there was a little decrease in $\mathrm{CH}_{4}$ over the porous dolomite pellets. By calculation with the following equation [16], it could be found that the product gas had a low heating value (LHV) of $12,141 \mathrm{~kJ}$ when $1 \mathrm{~kg}$ acetic acid was decomposed over the porous dolomite pellets, but only $10,790 \mathrm{~kJ}$ over the natural dolomite particles.

$H_{L}=\left(119,558 \mathrm{Y}_{\mathrm{H}_{2}}+45,895 \mathrm{Y}_{\mathrm{CH}_{4}}+10,115 \mathrm{Y}_{\mathrm{CO}}\right) / 100$

where, $H_{L}$ : the low heating value of product gas when $1 \mathrm{~kg}$ acetic acid was decomposed, $\mathrm{kJ} ; \mathrm{Y}_{\mathrm{H}_{2}}$ : yield of $\mathrm{H}_{2}$, wt\%; $\mathrm{Y}_{\mathrm{CH}_{4}}$ : yield of $\mathrm{CH}_{4}$, wt\%; $\mathrm{Y}_{\mathrm{CO}}$ : yield of $\mathrm{CO}$, wt\%.

The decomposition reaction of acetic acid could be expressed as follows:

$\mathrm{CH}_{3} \mathrm{COOH} \rightarrow \mathrm{Gas}\left(\mathrm{H}_{2}, \mathrm{CH}_{4}, \mathrm{O}_{2}, \mathrm{CO}, \mathrm{CO}_{2}\right.$, etc. $)+$ Coke

In addition, a series of reactions also occur [14]:

$\mathrm{CO}_{2}+4 \mathrm{H}_{2}=\mathrm{CH}_{4}+2 \mathrm{H}_{2} \mathrm{O}$

Table 1 - Yields of each gas component (wt\%) in acetic acid decomposition over different catalysts (bed temperature: $800{ }^{\circ} \mathrm{C}$, gas residence time: $7.5 \mathrm{~s}$ ).

\begin{tabular}{lccccc} 
Catalyst & $\mathrm{H}_{2}$ & $\mathrm{CH}_{4}$ & $\mathrm{O}_{2}$ & $\mathrm{CO}$ & $\mathrm{CO}_{2}$ \\
\hline Natural dolomite particles & 1.3 & 17.5 & 0.7 & 11.9 & 0 \\
Porous dolomite pellets & 1.8 & 16.1 & 5.1 & 25.7 & 42.5 \\
\hline
\end{tabular}

Y. Miao et al.

$$
\begin{aligned}
& \mathrm{CH}_{4}+2 \mathrm{O}_{2}=\mathrm{CO}_{2}+2 \mathrm{H}_{2} \mathrm{O} \\
& \mathrm{CH}_{3} \mathrm{COOH}+2 \mathrm{H}_{2} \mathrm{O}=2 \mathrm{CO}_{2}+4 \mathrm{H}_{2} \\
& \mathrm{C}+\mathrm{H}_{2} \mathrm{O}=\mathrm{CO}+\mathrm{H}_{2} \\
& \mathrm{CO}+\mathrm{H}_{2} \mathrm{O}=\mathrm{CO}_{2}+\mathrm{H}_{2}
\end{aligned}
$$$$
\mathrm{CH}_{4}+\mathrm{H}_{2} \mathrm{O}=\mathrm{CO}+3 \mathrm{H}_{2}
$$

It can be assumed that there are three stages in the decomposition reaction of acetic acid over catalysts, i.e., (1) diffusion of the acetic acid from the main gas stream to the external surface and then to the internal pores, (2) reactions on the external and internal surfaces, and (3) diffusion of the produced gas from the external and internal surfaces to the main gas stream. The catalytic activity increases with increasing of pore size and internal surface area, when the pore size is larger than $0.7 \mathrm{~nm}$ in diameter $[1,17]$. Therefore, the high catalytic activity of the porous dolomite pellets is attributed to the large pore size and high pore rate.

Although all of the tests in the present research work have been conducted with the cylindrical pellets of $3 \mathrm{~mm}$ in diameter and $4 \mathrm{~mm}$ in length, practical methods are available to make pellets of various sizes. The catalytic activity will increase with decreasing pellet size, since smaller pellets have larger specific surface area and lower resistance to gas diffusion within the pellets. Large pellets may be more suited to either fixed bed or moving bed reactors, while small pellets would normally be used in fluidized bed reactors.

\section{Conclusions}

(1) The porous dolomite pellets of $3 \mathrm{~mm}$ in diameter and $4 \mathrm{~mm}$ in height had a mechanical strength of $15 \mathrm{~N}$ and a pore rate of $0.75 \mathrm{~cm}^{3} \mathrm{~g}^{-1}$, when the clay/dolomite mass ratio was 0.4 and the $\mathrm{CMC} /$ dolomite mass ratio was 0.2 . The mechanical strength decreased, while the pore rate increased with increasing $\mathrm{CMC} /$ dolomite mass ratio. The pore size had approximately a normal distribution in the range of $0.06-200 \mu \mathrm{m}$.

(2) In the decomposition of acetic acid over the porous dolomite pellets, the yield of total product gas increased with increasing gas residence time and bed temperature at first, and then became constant when the gas residence time was longer than $7.5 \mathrm{~s}$ and the bed temperature was higher than $800^{\circ} \mathrm{C}$. A high yield of total product gas meant a low yield of coke.

(3) Under the condition of gas residence time at $7.5 \mathrm{~s}$ and bed temperature at $800{ }^{\circ} \mathrm{C}, 99.7 \mathrm{wt} \%$ of acetic acid was decomposed over the porous dolomite pellets, but only $36.5 \mathrm{wt} \%$ of acetic acid was decomposed over the natural dolomite particles, indicating that the porous dolomite pellets were more effective than the natural dolomite particles in catalyzing of tar decomposition to gas. 


\section{Acknowledgments}

This research project was financially supported by the National Hi-tech R\&D Program (2007AA05Z410) and National Key Technology R\&D Program (2006BAD07A0301).

\section{R E F E R E N C E S}

[1] El-Rub ZA, Bramer EA, Brem G. Review of catalysts for tar elimination in biomass gasification processes. Ind Eng Chem Res 2004;43:6911-9.

[2] Waltz E. Cellulosic ethanol booms despite unproven business models. Nat Biotechnol 2008;26:8-9.

[3] Coll R, Salvadó J, Farriol X, Montané D. Steam reforming model compounds of biomass gasification tars: conversion at different operating conditions and tendency towards coke formation. Fuel Process Technol 2001;74(1):19-31.

[4] Nordgreen T, Liliedahl T, Sjöström K. Elemental iron as a tar breakdown catalyst in conjunction with atmospheric fluidized bed gasification of biomass: a thermodynamic study. Energy Fuels 2006;20:890-5.

[5] Delgado J, Aznar MP, Corella J. Calcined dolomite, magnesite, calcite for cleaning hot gas from a fluidized bed biomass gasifier with steam: life and usefulness. Ind Eng Chem Res Eng Chem;35:3637-3643.

[6] Orio A, Corella J, Narvaez I. Performance of different dolomites on hot raw gas cleaning from biomass gasification with air. Ind Eng Chem Res 1997;36:3800-8.
[7] Devi L, Ptasinski KJ, Janssen FJJG. A review of the primary measures for tar elimination in biomass gasi cation processes. Biomass Bioenergy 2003;24:125-40.

[8] Olivares A, Aznar MP, Caballero MA, Gil J, Francés E, Corella J. Biomass gasification: produced gas upgrading by in-bed use of dolomite. Ind Eng Chem Res 1997;36:5220-6.

[9] Perez P, Aznar MP, Caballero AM, Gil J, Martın AJ, Corella J. Hot gas cleaning and upgrading with a calcined dolomite located downstream a biomass fluidized bed gasifier operating with steam-oxygen mixtures. Energy Fuels 1997; 11:1194-203.

[10] Xia F, Miao Y. Kinetic study of the catalytic cracking of biooil. Acta Energiae Solaris Sinica 2008;29(8):1034-7.

[11] Li W, Yan Y, Li T, Ren Z, Huang M, Wang J, et al. Preparation of hydrogen via catalytic gasification of residues from biomass hydrolysis with a novel high strength catalyst. Energy Fuel 2008;22(2):1233-8.

[12] Zhang S, Yan Y, Li T, Ren Z. Upgrading of liquid fuel from the pyrolysis of biomass. Bioresour Technol 2005;96:545-50.

[13] Galdámez JR, García L, Bilbao R. Hydrogen production by steam reforming of bio-oil using coprecipitated $\mathrm{Ni}-\mathrm{Al}$ catalysts. Acetic acid as a model compound. Energy Fuels 2005;19:1133-42.

[14] Basagiannis AC, Verykios XE. Reforming reactions of acetic acid on nickel catalysts over a wide temperature range. Appl Catal A: Gen 2006;308:182-93.

[15] Miao Y, Xia F. A dolomite pellet catalyst, its preparation process and application. Patent: ZL200710024993.6.

[16] Yao Y, Xie T, Gao Y. Physical chemistry handbook. Shanghai: Shanghai Scientific \& Technical Publishers; 1985.

[17] Satrio JA, Shanks BH, Wheelock TD. A combined catalyst and sorbent for enhancing hydrogen production from coal or biomass. Energy Fuels 2007;21:322-6. 